\title{
Overview on Combat-oriented Equipment Maintenance Support Effectiveness Evaluation
}

\author{
Zhen Li", Jianping Hao, Cuijuan Gao, Xingxin Li, Fei Ye \\ Shijiazhuang Campus, Army Engineering University of PLA, Shijiazhuang 050003, China \\ *Corresponding author.
}

\begin{abstract}
Under the situation that the army vigorously advocates combat-oriented training, equipment maintenance support effectiveness evaluation must be combat-oriented, so as to obtain meaningful evaluation conclusions. Combined with the current background of combat-oriented training of troops, this paper summarizes the main definitions, evaluation elements, evaluation process and other basic contents of maintenance support effectiveness evaluation, analyzes three key issues: definition of important concepts, construction of index system and application of evaluation methods, combs out representative viewpoints, summarizes the shortcomings and challenges in combatoriented evaluation, and puts forward prospects for future development. The research results enrich the research content of combat-oriented maintenance support effectiveness evaluation, and have certain guiding significance for the follow-up research.
\end{abstract}

Keywords: Equipment maintenance support, effectiveness evaluation, index system, evaluation method, big data

\section{Introduction}

In recent years, the army has vigorously advocated combat-oriented training, aiming at improving the capability of preparing for war. In the field of equipment maintenance support, military high-level officials paid great attention to the actual maintenance support effectiveness after the reform, and instructed all services, arms and theaters to carry out training on actual military, installed and all-factor equipment maintenance support under combat-oriented conditions, to find problems in time and improve them, and put forward the question of combat-oriented evaluation: How strong is the current actual maintenance support effectiveness? What is the gap from the combatoriented requirements? How to ensure maintenance support after reform.

Previous research of maintenance support effectiveness evaluation mainly started from the point of view of equipment maintenance support elements, objects or system operation, and then carried out effectiveness evaluation. He et al.[1] put forward a multi-layer equipment maintenance support effectiveness evaluation index system, and designed a combination weighting method combining improved analytic hierarchy process and principal component analysis, which effectively solved the problem of consistency and subjective randomness of judgment matrix when there were too many indexes in analytic hierarchy process. On the basis of scientific analysis of shipyards and maintenance support resources, Feng et al. [2] used the evaluation method based on fuzzy analytic hierarchy process (FAHP) to evaluate the shipbuilding and repair capabilities of shipyards, which effectively improved the efficiency of manufacturing and maintenance resources. Zhou et al. [3] designed an analysis model based on multi-quality characteristics instead of statistical data in combat phase, and studied a model integration method, which integrated reliability model, testability model and maintainability model into the support effectiveness evaluation model, which can effectively improve the combat capability of aviation equipment. These studies have achieved good results, but because the concept of combat-oriented evaluation is not introduced, there is still a big gap between them and answering the question of combat-oriented evaluation. There are still few studies that really carry out evaluation based on tasks and can clearly answer "yes or no" instead of giving a set of effectiveness values, which obviously cannot achieve the ideal combat-oriented evaluation effect.

In order to explore the direction of combat-oriented maintenance support effectiveness evaluation, this paper

ISSN: 0010-8189

(C) CONVERTER 2020

www.converter-magazine.info 
summarizes equipment maintenance support effectiveness evaluation based on current combat-oriented training, in order to provide ideas and suggestions for combat-oriented maintenance support evaluation research.

\section{Basic Content Analysis}

\subsection{Main definitions}

According to current literature, the concept and connotation of equipment maintenance support effectiveness evaluation have not formed a unified understanding, and there have been many understandings and expositions. Liu et al. [4] believe that equipment maintenance support effectiveness refers to the effectiveness of the equipment support organization used to perform specific maintenance support tasks to achieve the expected goals, which is a dynamic concept. Wang et al. [5] believe that equipment maintenance support is the general term for various technical measures and related support activities taken to maintain and restore good technical performance of equipment. Zhong et al. [6] believe that maintenance support capability of electronic information equipment is its ability to use various support resources to ensure the completion of electronic information equipment maintenance tasks, and is the ability to ensure that electronic information equipment is maintained, restored or improved to a prescribed technical state. Based on the understanding of above scholars, this paper gives the following definitions:

Equipment maintenance support is the general term for various technical measures and related support activities taken to maintain and restore good technical performance of equipment;

Equipment maintenance support effectiveness evaluation is mainly to evaluate maintenance support system construction and operation level, measure comprehensive capabilities, find problems in system construction and operation, and then optimize and improve the functions, elements, structure and operation of maintenance support system, or improve equipment maintenance support plan, model, method and style, and finally form a "construction-evaluation-reconstruction" circular development model, and constantly improve precision and scientific support level of equipment.

\subsection{Evaluation elements}

Generally speaking, maintenance support effectiveness evaluation problem is mainly composed of five elements: evaluator, evaluation object, index system, weight coefficient, evaluation model [7]. Each element is an important part in the process of realizing evaluation goal.

The evaluator determines the position of effectiveness evaluation. The success of evaluation activities depends on whether the evaluators' evaluation needs are met. In maintenance support effectiveness evaluation, the evaluator can be either the maintenance support unit concerned with maintenance support results or the combat commander concerned with maintenance support effects. The level and position of the two are different, and the height and overall situation of the latter is greater than that of the former.

The evaluation object is the carrier of evaluation activities, which is usually maintenance support system. Due to different evaluation objectives, maintenance support system can be either a static system or a dynamic system that implements maintenance support activities.

The construction of maintenance support effectiveness index system is the basis of maintenance support effectiveness evaluation, which determines the scientificity and credibility of evaluation conclusions. The construction of index system is a complicated and difficult system engineering, which should consider many elements in maintenance support system and the relationship between them.

When index system is well established, another important issue is the determination of weight coefficient. Generally, there are three methods to determine the weight coefficient: subjective weighting method, objective weighting method and combination weighting method [8]. Each of the three methods has its own advantages and

ISSN: 0010-8189

(C) CONVERTER 2020

www.converter-magazine.info 
disadvantages, and should be selected according to the type of index system, with the best characterization of index system.

Evaluation method, also called evaluation model, is a research hotspot in this field, which mainly synthesizes index values with different weights after assignment into a comprehensive effectiveness value through a specific mathematical model. In the case of various evaluation methods, it is also an important research work to choose appropriate evaluation methods according to evaluation objectives, evaluation preferences and characteristics of evaluation objects.

\subsection{Evaluation process}

Based on main definition and evaluation elements, combined with the research of other scholars, the basic process of equipment maintenance support effectiveness evaluation is established, as shown in Figure 1.

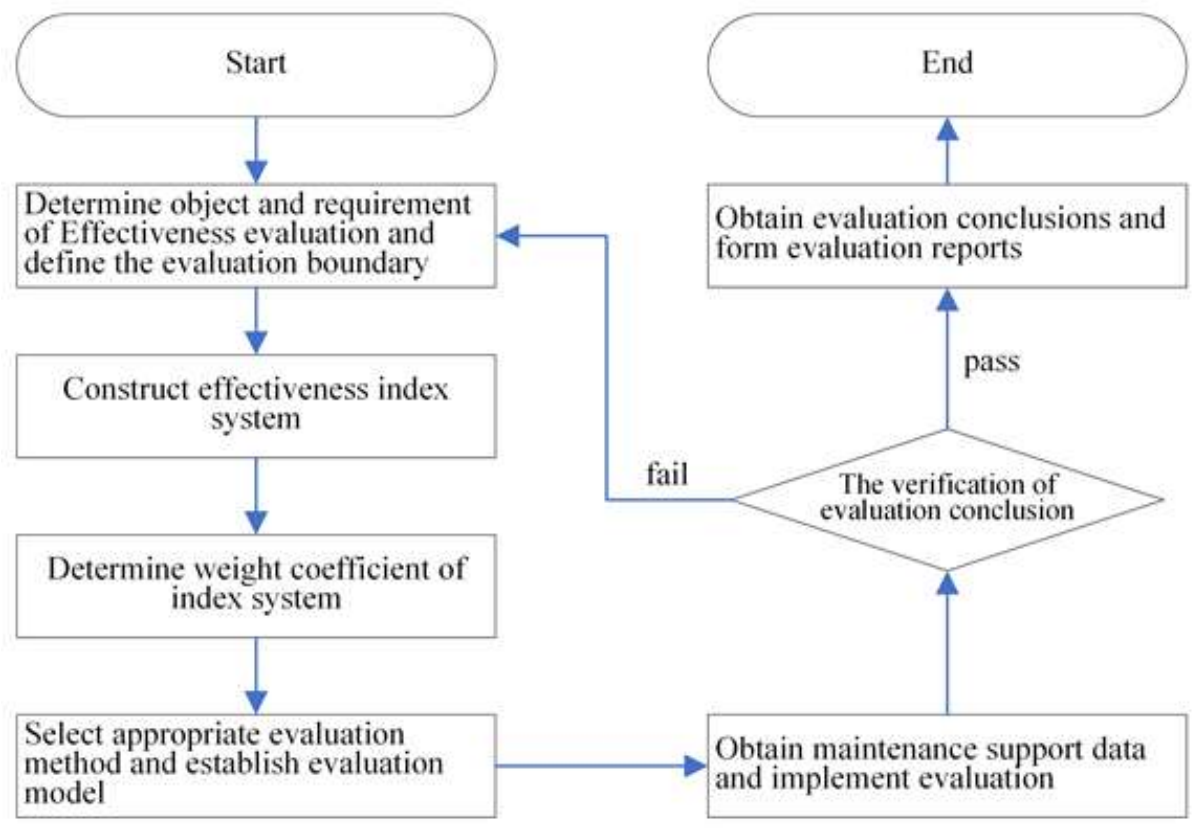

Figure 1. Basic process of equipment maintenance support effectiveness evaluation

(1) Determine the object and purpose of equipment maintenance support effectiveness evaluation, analyze the needs of effectiveness evaluation, and clarify the boundary of effectiveness evaluation;

(2) Use scientific methods to construct a systematic, scientific and reasonable effectiveness index system, including index selection and index standardization;

(3) Apply appropriate methods to determine the weight coefficient of index system;

(4) Based on information such as evaluation purpose, evaluation preferences, and characteristics of evaluated system, select an appropriate evaluation method and establish a maintenance support effectiveness evaluation model;

(5) Obtain as comprehensive maintenance support evaluation data as possible, and implement maintenance support effectiveness evaluation activities according to selected evaluation method;

(6) Inspection of maintenance support effectiveness evaluation results.

(7) Draw an evaluation conclusion, form an evaluation report, and achieve the purpose of the evaluation.

\section{Analysis of Key Issues}

The definition of important concepts, construction of index system and application of evaluation methods have the most critical influence on scientificity and credibility of evaluation conclusion of maintenance support effectiveness, which need to be discussed and analyzed emphatically. This paper calls it the key problem. By combing

ISSN: 0010-8189 
representative viewpoints, and then comparing with requirements of combat-oriented evaluation, the existing problems are analyzed.

\subsection{Differentiation of important concepts}

In the research of maintenance support effectiveness evaluation, two groups of concepts (effectiveness-capability, evaluation-assessment) with similar meanings and mixed use appear, and their usage is generally determined according to the researcher's own understanding. In fact, there are some differences between them. If they can't be clearly defined and differentiated, they will inevitably lead to cognitive deviation and affect evaluation effect. Traverse the relevant literature, main representative views are shown in Table 1.

Table 1. Differentiation of maintenance support effectiveness evaluation concept

\begin{tabular}{|c|c|c|c|}
\hline Category & Sort & View & Ref. \\
\hline \multirow{6}{*}{$\begin{array}{l}\text { Effectiveness - } \\
\text { capability }\end{array}$} & 1 & $\begin{array}{l}\text { Effectiveness cannot be produced out of thin air, nor can it exist independently. There } \\
\text { must be a "main body" that can be hosted and an "activity process" on which it } \\
\text { functions. For the equipment maintenance support effectiveness, this "main body" is } \\
\text { the equipment maintenance support system, and the "activity process" is the } \\
\text { maintenance support activity process. }\end{array}$ & [9] \\
\hline & 2 & $\begin{array}{l}\text { "Maintenance support capability" describes the "capacity" or "potential" of the } \\
\text { system itself, which is a static and instantaneous concept; while "maintenance support } \\
\text { effectiveness" describes the impact degree of the equipment maintenance support } \\
\text { system transforming potential capabilities into actual effects, which is a dynamic } \\
\text { process concept. }\end{array}$ & [10] \\
\hline & 3 & $\begin{array}{l}\text { "Maintenance support capability" refers to the degree of satisfaction of the } \\
\text { maintenance support requirements of the system. It pays more attention to the input } \\
\text { of the quantity and quality of maintenance support resources, and less concerned } \\
\text { about the output. It is a description of the ability of the maintenance support system, } \\
\text { which is a relatively static concept; and "maintenance support effectiveness" refers to } \\
\text { the actual effect of the system in the process of using existing maintenance support } \\
\text { capabilities to complete specific support tasks. }\end{array}$ & [11] \\
\hline & 4 & $\begin{array}{l}\text { A time-condition-task three-dimensional space for equipment maintenance support } \\
\text { can be established. "Maintenance support effectiveness" is the volume of the entire } \\
\text { three-dimensional space, and "maintenance support capability" is a section obtained } \\
\text { by cutting any axis in the three-dimensional space. }\end{array}$ & [4] \\
\hline & 5 & $\begin{array}{l}\text { The index system established around "capability" only studies "potential" or } \\
\text { "potential + potential", which mainly reflects the ability of the equipment } \\
\text { maintenance support system under non-confrontational conditions; the index system } \\
\text { around "effectiveness" only studies "Significant energy", which mainly reflects the } \\
\text { ability of the equipment maintenance support system under confrontation conditions. } \\
\text { Both kinds of research can't reflect the whole picture of equipment maintenance } \\
\text { support capability, so the capability generation mechanism of potential-potential- } \\
\text { apparent energy is put forward, and the capability and efficiency are considered } \\
\text { together. }\end{array}$ & [12] \\
\hline & 6 & $\begin{array}{l}\text { In combat situations, "wartime equipment maintenance support capability" refers to } \\
\text { the ability of the equipment maintenance support system to repair damaged } \\
\text { equipment to a prescribed state under battlefield conditions; "Wartime equipment } \\
\text { maintenance support effectiveness" is the ability of the maintenance support system } \\
\text { to complete the maintenance support tasks given by the combat process under } \\
\text { battlefield conditions. }\end{array}$ & [13] \\
\hline $\begin{array}{l}\text { Evaluation - } \\
\text { assessment }\end{array}$ & 1 & $\begin{array}{l}\text { "Evaluation" refers to the behavior of measuring the characteristics of an object } \\
\text { according to a clear goal and turning it into subjective utility, that is, the process of } \\
\text { clarifying the value; The "evaluation" mainly adopts qualitative and quantitative } \\
\text { methods, and pays equal attention to objective statistical data and subjective } \\
\text { descriptive data, thus ensuring the objectivity of the conclusion. }\end{array}$ & [14] \\
\hline
\end{tabular}

It can be seen that most researchers pay attention to the concept of effectiveness-ability, but less research on evaluation-evaluation.

ISSN: 0010-8189 
In the aspect of effectiveness-capability. The first three viewpoints all put forward the concept of "static and dynamic", that capability is static and effectiveness is dynamic; point 4 constructs a three-dimensional space of maintenance support effectiveness, and capability belongs to an arbitrary section of the three-dimensional space; point 5 proposes the ability generation mechanism of potential-potential energy-significant energy, and believes that the capability under non-confrontation conditions and the effectiveness under confrontation conditions must be combined to fully reflect the full picture of equipment maintenance support effectiveness; point 6 discusses the combat situation and believes that capability are mostly used for description single activity, effectiveness is used to describe the overall task. These points have essentially the same understanding of effectiveness-capability, and they can all be summarized as: capability is static, which is the ability of the system itself to do things, and effectiveness is dynamic, and is the degree to which a certain task can be completed in combination with specific environments and conditions. It can be considered that "effectiveness = capability + other factors", other factors include background, environment, conditions, activities, etc. The maintenance support level of maintenance support system when performing tasks is the valuable information, so combat-oriented evaluation should aim at the dynamic effectiveness.

In the aspect of assessment-evaluation. There are few researches in this area, and scholars don't go deep in their use, and often choose one based on personal preference or subject habits. There are some problems. Due to the numerous maintenance support activities, there are not only suitable for assessment, but also suitable for evaluation. The difference between assessment and evaluation is not small enough to be used at will. If its usage is not clear, it will affect the overall effectiveness assessment. Based on related literature research and multiple dictionary definitions, this article believes that: (1) The term "assessment" has two meanings, including "asset assessment" and "general evaluation"; "evaluation" only includes the latter meaning. (2) When expressing "general evaluation", the difference between the two terms is generally not obvious; If studied in detail, each has its own emphasis. "Assessment" emphasizes the process, and conclusions are used as the basis for the next action, and "evaluation" emphasizes results. (3) "Evaluation" is more subjective than "assessment". (4) "evaluation" generally adopts a qualitative method, and "assessment" adopts a combination of qualitative and quantitative methods. To sum up, when describing the overall content of evaluation activities, calculating weight coefficient and implementing evaluation model, the use of "evaluation" reflects the objectivity and quantification of mathematics; When constructing index system, it is sometimes necessary to refer to expert opinions, and then "evaluation" is used to reflect subjective evaluation intention of the evaluator.

\subsection{Construction of index system}

As an important work of maintenance support effectiveness evaluation, the construction of index system has been concerned by researchers, and has accumulated a wealth of research results. Aiming at the problem of index system construction, it can be analyzed from two aspects: index system category and index system construction method category.

As far as index system category is concerned, it can be divided into index system of equipment maintenance support in peacetime and wartime. Among them, index system of wartime equipment maintenance support is mainly based on the battlefield environment, wartime maintenance support tasks and characteristics; The index system of peacetime equipment maintenance support is mainly constructed based on the tasks and characteristics of peacetime maintenance support, which generally starts from three angles: the components of maintenance support system, the operation of maintenance support system and the maintenance support objects.

Compared with the index system categories, combing and analyzing the index system construction method categories can analyze the advantages and disadvantages of index system at the method level, improve it, and build a more suitable index system, which is obviously more valuable and meaningful. The main methods are shown in Table 2 .

The index system itself is a kind of relatively "soft" information, which does not have a strict reasoning and verification process. Therefore, the construction method of index system tends to be soft theory, which makes most researchers still rely on human experience to determine the index system even when using the construction method of non-expert investigation. If we trace the essence of methods, these methods all belong to the expert investigation method in essence, or improve the expert investigation method from different angles. 
Table 2. Construction method of maintenance support effectiveness index system

\begin{tabular}{|c|c|c|c|}
\hline \multicolumn{2}{|r|}{ Category } & Content & Ref. \\
\hline \multirow{6}{*}{$\begin{array}{l}\text { a. } \\
\text { Delphi } \\
\text { method }\end{array}$} & $\begin{array}{l}\text { a-1. Conventional } \\
\text { method }\end{array}$ & $\begin{array}{l}\text { The Delphi method can give full play to the role of experts and is easy to } \\
\text { implement, but its shortcomings are also obvious, such as the lack of } \\
\text { communication between experts; it is easily affected by the subjective } \\
\text { influence of the organizer; it is easy to ignore the opinions of a few people, } \\
\text { leading to deviations from reality. }\end{array}$ & [15] \\
\hline & $\begin{array}{l}\text { a-2. Break down } \\
\text { overall } \\
\text { effectiveness }\end{array}$ & $\begin{array}{l}\text { Decomposing the overall effectiveness into several parts, constructing the } \\
\text { index system separately and then summarizing it can effectively reduce the } \\
\text { difficulty of construction. For example, it can be divided into two aspects: } \\
\text { maintenance effectiveness and equipment supply effectiveness; or into four } \\
\text { aspects: time, cost, personnel, and maintenance effect. }\end{array}$ & [16] \\
\hline & $\begin{array}{c}\text { a-3. Consider static }+ \\
\text { dynamic }\end{array}$ & $\begin{array}{l}\text { Considering not only the static index system of the maintenance support } \\
\text { system, but also the dynamic index system of its operation, the index } \\
\text { system is established separately and finally integrated. }\end{array}$ & [17] \\
\hline & $\begin{array}{l}\text { a-4. Introduce } \\
\text { potential factors }\end{array}$ & $\begin{array}{l}\text { In the evaluation based on the existing results, the potential factors in the } \\
\text { maintenance support elements are also considered, and the comprehensive } \\
\text { effectiveness evaluation and potential evaluation are established to } \\
\text { establish an index system to improve the comprehensiveness of the index } \\
\text { system. }\end{array}$ & [10] \\
\hline & $\begin{array}{l}\text { a-5. Introduce } \\
\text { flexibility factor }\end{array}$ & $\begin{array}{l}\text { In the process of constructing the index system, the flexibility factor based } \\
\text { on the combination of capability vector decomposition method and analytic } \\
\text { hierarchy process is introduced to enhance the adaptability and flexibility } \\
\text { of the index system. }\end{array}$ & [18] \\
\hline & $\begin{array}{l}\text { a-6. Use quality } \\
\text { function deployment } \\
\text { for index screening }\end{array}$ & $\begin{array}{l}\text { After the maintenance support index system is constructed through the } \\
\text { Delphi method, the quality function deployment is used to map the } \\
\text { maintenance support operational requirements to the maintenance support } \\
\text { index screening requirements, which can streamline the index system and } \\
\text { eliminate indicator redundancy. }\end{array}$ & [19] \\
\hline \multicolumn{2}{|c|}{$\begin{array}{l}\text { b. Task-based construction } \\
\text { method }\end{array}$} & $\begin{array}{l}\text { By analyzing the combat process, the maintenance support mission profile } \\
\text { is obtained; The continuous adjacent mapping of mission profile, } \\
\text { maintenance support capability and maintenance support index is } \\
\text { established, and the mapping matrix of maintenance support task and } \\
\text { maintenance support index is obtained, thus the maintenance support index } \\
\text { system based on maintenance support task is constructed. }\end{array}$ & {$[20]$} \\
\hline \multicolumn{2}{|c|}{$\begin{array}{l}\text { c. Construction method based on } \\
\text { capability generation mechanism }\end{array}$} & $\begin{array}{l}\text { Aiming at the limitations of the traditional equipment support system } \\
\text { effectiveness evaluation index system, the article analyzes the capability } \\
\text { generation mechanism and defines the three-stage capability presentation } \\
\text { form of equipment maintenance support: support potential-support } \\
\text { potential energy-support apparent energy. A maintenance support index } \\
\text { system based on "three capabilities" is proposed. }\end{array}$ & {$[21]$} \\
\hline
\end{tabular}

Some researchers build the index system by establishing the mapping of task-ability-index, which can ensure that the constructed index system fully represents the execution task and enhance the credibility of evaluation conclusion. This method is based on task development, which is more in line with the characteristics of combatoriented evaluation with task completion as the fundamental core, and will be a feasible way to build combatoriented maintenance support index system.

The construction method based on the capability generation mechanism mainly studies the capability composition, which can be regarded as enriching the "capability" elements in the mapping chain of method (2).

\subsection{Application of evaluation method}

The application of evaluation method is the research focus on maintenance support effectiveness evaluation. At present, there are abundant researches on evaluation methods, which can be summarized into five types, as shown in Table 3.

ISSN: 0010-8189 
The first category is multi-index comprehensive evaluation method. This kind of method generally evaluates the maintenance support effectiveness by weighting and synthesizing the lower index and obtaining the upper index value.

The second category is uncertainty theory. This kind of method combines the fuzziness and randomness of uncertain factors closely, realizes the mutual transformation between qualitative concepts and quantitative values, and provides an effective solution for dealing with uncertain data.

The third category is simulation evaluation method. This kind of method mainly simulates maintenance support activities by building a computer model, and obtains evaluation data from it to carry out evaluation activities.

The fourth category is intelligent algorithm. This kind of method mainly applies artificial intelligence theory and technology, and establishes intelligent evaluation model to evaluate effectiveness.

The fifth category is the combination model evaluation method. That is, a combination of the above methods.

Table 3. Evaluation method of equipment maintenance support effectiveness

\begin{tabular}{|c|c|c|c|c|}
\hline Category & Inclusion method & Advantage & Disadvantage & Ref. \\
\hline $\begin{array}{l}\text { Multi-index } \\
\text { comprehensive } \\
\text { evaluation method }\end{array}$ & $\begin{array}{l}\text { AHP, linear weighting } \\
\text { method, multi-level } \\
\text { extension } \\
\text { comprehensive } \\
\text { evaluation method, ideal } \\
\text { point method, data } \\
\text { envelopment analysis } \\
\text { method }\end{array}$ & $\begin{array}{l}\text { The method is systematic, } \\
\text { concise and practical, with } \\
\text { wide application range } \\
\text { and strong applicability. }\end{array}$ & $\begin{array}{l}\text { (1) There are many } \\
\text { qualitative components with } \\
\text { certain subjectivity; (2) } \\
\text { When there are too many } \\
\text { indicators, the data statistics } \\
\text { are large and it is difficult to } \\
\text { control the sample size. }\end{array}$ & {$[22]$} \\
\hline Uncertainty theory & $\begin{array}{l}\text { Fuzzy comprehensive } \\
\text { evaluation method, } \\
\text { rough set theory, cloud } \\
\text { theory, } \\
\text { comprehensive gray } \\
\text { evaluation method }\end{array}$ & $\begin{array}{l}\text { Consider the influence of } \\
\text { fuzzy factors and random } \\
\text { factors to make the } \\
\text { evaluation results more } \\
\text { objective. }\end{array}$ & $\begin{array}{l}\text { (1) The determination of } \\
\text { concepts and thresholds } \\
\text { sometimes needs to be } \\
\text { judged by human } \\
\text { experience; (2) When the } \\
\text { sample size is large, the } \\
\text { ability to deal with random } \\
\text { factors decreases. }\end{array}$ & [23] \\
\hline $\begin{array}{l}\text { Simulation evaluation } \\
\text { method }\end{array}$ & $\begin{array}{l}\text { Monte Carlo simulation, } \\
\text { system dynamics } \\
\text { simulation, discrete } \\
\text { event system simulation, } \\
\text { agent simulation, }\end{array}$ & $\begin{array}{l}\text { The complex interaction } \\
\text { among random factors, } \\
\text { systems and environments } \\
\text { can be simulated by } \\
\text { computer, and the } \\
\text { performance evaluation } \\
\text { value can be obtained } \\
\text { quickly. }\end{array}$ & $\begin{array}{l}\text { (1) The simulation model is } \\
\text { difficult to establish and not } \\
\text { universal; (2) Sometimes it } \\
\text { is difficult to simulate real } \\
\text { environmental conditions. }\end{array}$ & {$[24]$} \\
\hline Intelligent Algorithm & $\begin{array}{lr}\text { Artificial } & \text { neural } \\
\text { network, } & \text { genetic } \\
\text { algorithm, } & \text { Bayesian } \\
\text { network, } & \text { association } \\
\text { analysis } & \\
\end{array}$ & $\begin{array}{l}\text { It has strong robustness, } \\
\text { memory ability and strong } \\
\text { self-learning ability. }\end{array}$ & $\begin{array}{l}\text { The construction of the } \\
\text { model is complicated, which } \\
\text { requires high quantity and } \\
\text { quality of training samples. }\end{array}$ & [6] \\
\hline $\begin{array}{l}\text { Combined model } \\
\text { evaluation method }\end{array}$ & $\begin{array}{l}\text { A combination of the } \\
\text { above methods }\end{array}$ & $\begin{array}{l}\text { It can make up for the } \\
\text { limitation of single } \\
\text { method and obtain more } \\
\text { accurate and credible } \\
\text { evaluation results. }\end{array}$ & $\begin{array}{l}\text { Due to the mutual exclusion } \\
\text { of models or improper } \\
\text { selection of methods, the } \\
\text { evaluation effect is reduced. }\end{array}$ & {$[25]$} \\
\hline
\end{tabular}

\section{Challenges and Future Prospects}

ISSN: 0010-8189

(C) CONVERTER 2020

www.converter-magazine.info 
(1) At present, the training of troops is continuously strengthened, aiming at improving the combat-oriented level. With the deepening of requirements of combat-oriented evaluation, the index system construction method based on expert investigation method is gradually found to be difficult to overcome the defects of strong subjectivity, and lacks the scientific and credibility of evaluation. To evaluate equipment maintenance support effectiveness, an index system construction method that can truly represent combat-oriented maintenance support effectiveness is urgently needed. Guided by the core essence of combat-oriented evaluation, some researchers have explored taskbased construction methods and achieved certain results, but the standardization of construction procedures is not yet mature. In this respect, we can learn from the thinking of system engineering [26], construct the V-shaped diagram of maintenance support effectiveness evaluation, and use the left side of $\mathrm{V}$-shaped diagram to standardize the index system construction procedure, as shown in Figure 2. The left side of the V-shaped diagram shows the index system construction process, the bottom part shows the maintenance support system test, and the right side shows the evaluation process. The operation flow direction is shown by the gray arrow in the figure. The left index system construction method takes the maintenance support top task-"Mission" as the top level, and designs three levels: maintenance support mission, maintenance support task and maintenance support system. By determining the corresponding relationship mapping through the characteristics association of each level, the traceability of indicators at each level is ensured, so that each indicator can be traced back to the top-level "maintenance support mission", and the assumption that the indicator system fully serves the top-level task is realized. In addition, the Vshape diagram of maintenance support effectiveness evaluation realizes the perfect flow from top task decomposition to bottom index, and then from index effectiveness aggregation to overall effectiveness, which is a good strategy to carry out combat-oriented maintenance support effectiveness evaluation.

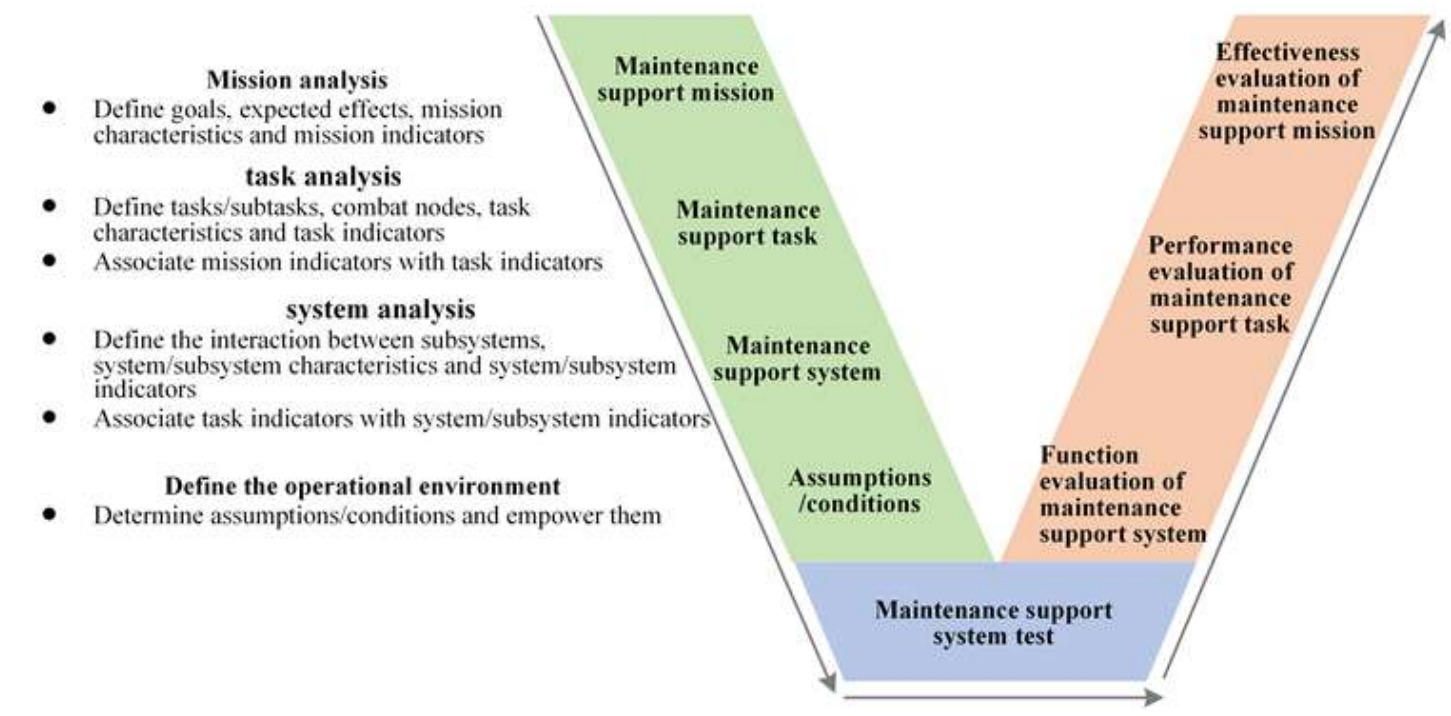

Figure 5. V-shaped chart of equipment maintenance support effectiveness evaluation

(2) With the advent of big data era, the equipment maintenance support data shows a trend of massive growth. The ability to store, process and analyze big data in maintenance support will be an important support for combatoriented maintenance support effectiveness. However, at present, there is little research in this field, and combat units have not paid enough attention to maintenance support data, resulting in the failure to form a systematic and organized maintenance support big data ecosystem, low data utilization rate and calculation accuracy, and even some important data are lost or abandoned [5].

In view of the huge amount of maintenance support data with scattered sources and diverse formats, a maintenance support big data ecosystem composed of all factors and multiple participants should be established, and a maintenance support equipment data cloud platform should be constructed. On the one hand, it can enhance the efficient storage and processing ability of data. On the other hand, it can realize data exchange and sharing between combat equipment, combat units and even military and civilian sides on the cloud platform, forming a brand-new

ISSN: 0010-8189

(C) CONVERTER 2020

www.converter-magazine.info 
data sharing pattern with full coverage of subjects and full connectivity of elements, and effectively playing an important role in maintaining and supporting big data.

(3) With the rapid development of military science and technology, the future war forms are gradually evolving, and the equipment maintenance support is developing towards integration, integration and informationization. The traditional effectiveness evaluation methods are gradually incompetent in massive data processing, fuzzy evaluation of multiple random factors and battlefield environment simulation. Only by adapting to operational changes in time and introducing updated evaluation methods can we effectively ensure the credibility of combatoriented maintenance support effectiveness evaluation of. At present, with the continuous development of information technology new generation, advanced theories and technologies such as artificial intelligence, Internet of Things and cloud computing are changing the whole social form. These theories and technologies are of great help to expand the evaluation methods of equipment support effectiveness. More and more researchers use artificial intelligence methods such as genetic algorithm and neural network to carry out effectiveness evaluation $[6,27,28]$, which solves the problem that traditional evaluation methods are difficult to deal with huge sample size, effectively improves the evaluation speed and accuracy, and provides help for the optimization and improvement of maintenance support effectiveness in the information age.

\section{Conclusions}

Combined with the current actual combat training background, this paper focuses on three key issues: definition of important concepts, construction of index system and application of evaluation methods, and combs out the representative viewpoints, thus summing up the shortcomings and challenges in various aspects, and looking forward to the future development of maintenance support effectiveness evaluation. The research results enrich the research content of combat-oriented maintenance support effectiveness evaluation, which is helpful for relevant researchers to understand the research status, challenges and development trends in this field, and has certain guiding significance for the follow-up research.

\section{Acknowledgements}

This work was supported in part by the National Defense Pre-research Fund (9140A27010215JB34422).

\section{References}

[1] Y. He, F. Hu, L. Lv, C. Zhou, X. Xiao, L. Wang, "Research on Effectiveness Evaluation of Equipment Maintenance Support Based on Simulation," In 2019 International Conference on Intelligent Computing, Automation and Systems (ICICAS), IEEE: Chongqing, China, 2019, https://doi.org/10.1109/ICICAS48597, 00079, pp 339-343, 2019.

[2] $X$. Feng, L. Feng, "TECHNOLOGY OF SHIP MAINTENANCE SUPPORT RESOURCE CAPABILITY BASED ON FUZZY HIERARCHY METHOD," pp. 9.

[3] Y. Zhou, Zeng, Z. Jia, Y. Zhou, K. Yuan, "Multi-Quality Characteristics Model Integration of Aviation Equipment for Support Effectiveness Evaluation," https://doi.org/10. 12783/dtcse/cmee2017/20033, no. cmee, dtcse, 2018.

[4] W. Liu, X. Jia, G. Wang, Q. Hu, "Design and Implementation of Equipment Maintenance Support Effectiveness Evaluation System Based on Multi-Agent Simulation," Firepower and Command Control, vol. 38, no. 01, pp. 50-53, 2013.

[5] S. Wang, Q. Hu, F. Li, Q. Wang, "Review of Research on Effectiveness Evaluation of Equipment Maintenance Support," Systems Engineering and Electronics, vol. 41, no. 10, pp. 2271-2278, 2019.

[6] J. Zhong, H. Zhang, Z. Ma, "BP Neural Network Evaluation of Maintenance Support Capability of Electronic Information Equipment," Modern Electronic Technology, vol. 38, no. 02, pp. 11-14, 2015.

[7] Y. Shuai, T. Song, J. Wang, H. Shen, W. Zhan, "Equipment Support Capability Assessment Review," Computer Measurement and Control, vol. 24, no. 03, pp. 1-3+7, 2016. 
[8] J. Wen, Q. Li, "A Method to Analysis Maintenance Support Capability of Aircraft Based on QFD. In 2009 8th International Conference on Reliability," Maintainability and Safety, IEEE: Chengdu, China, https://doi.org/10.1109/ICRMS, 2009, 5270114, pp. 621-625, 2009.

[9] C. Liu, X. Du, F. Li, "Equipment maintenance support effectiveness evaluation index system," Sichuan Ordnance Journal, vol. 30, no. 10, pp. 120-123, 2009.

[10] X. Wang, "Research on Evaluation of Military Equipment Support Ability," Journal of Ordnance Engineering College, no. 01, 2002.

[11] Y. Guo, D. Chen, "Evaluation model of aviation equipment maintenance support ability in wartime," Firepower and command and control, vol. 35, no. 10, pp. 166-170, 2010.

[12] Y. Yue, H. Yang, "Research on Capability Evaluation Index System of Equipment Support System Based on Capability Generation Mechanism," Military Operations Research and System Engineering, vol. 26, no. 03, pp. 46-50, 2012.

[13] T. Zhang, J. Zhang, Guo, B., Tan, Y., "Research on Evaluation Index System of Maintenance Support Capability of Equipment in Use Phase," Journal of the Academy of Armored Forces Engineering, no. 01, pp. 11-14+32, 2005.

[14] S. Zheng, W. Wang, "Discrimination and Translation of "Evaluation" and "Evaluation" in the Field of Equipment Maintenance Support," Chinese Technical Terms, vol. 14, no. 03, pp. 27-32, 2012.

[15] Q. Chen, "Research Status and Development of Equipment Support Capability Evaluation Modeling," Journal of Equipment Academy, vol. 23, no. 02, pp. 1-4+127, 2012.

[16] S. Zuo, "Research on Evaluation and Optimization of Armored Equipment Maintenance Support System," Master, National University of Defense Technology, 2010.

[17] H. Yuan, Z. Feng, Y. Wang, T. Zhang, L. Ren, "Preliminary Study on the Evaluation of Armored Equipment Maintenance Support Ability," Acta Armamentarii (Tanks, Armored Vehicles and Engines), no. 03, pp. 59-64, 2000.

[18] T W. ang, Z. Wang, Y. Wang, Z. Peng, Q. Chen, "Research on Evaluation Index System of Complex Equipment Maintenance Support Capability, In Technological Fusion Innovation, Reliable Service Enterprise, Winning of Safety Products-Proceedings of the 2013 National Mechanical Industry Reliability Technology Academic Exchange Conference and the Fifth General Assembly of the Fourth Reliability Engineering Branch; Reliability Engineering Branch of Chinese Mechanical Engineering Society," School of Mechanical and Automatic Control, Zhejiang Sci-Tech University, pp. 4, 2013.

[19] Y. Zhang, H. Fu, W. Ma, S. Li, "QFD-KLEE-based evaluation index system for maintenance and support capability of new armored mechanized forces," Value Engineering, vol. 36, no. 19, pp. 12-15, 2017.

[20] B. Zhu, S. Go, L. Tan, "Task-oriented Modeling of Equipment Maintenance Support Capability Evaluation," In 2008 Symposium on System Simulation Technology and Its Application; Professional Committee of System Simulation of Chinese Society of Automation, Professional Committee of Simulation Technology Application of Chinese Society of System Simulation, pp. 4, 2008.

[21] C. Zhang, X. Wu, C. Gong, H. Zhang, "Research on Equipment Support Capability Generation Based on Organizational Learning Theory," Journal of the Academy of Equipment Command and Technology, vol. 21, no. 02, pp. 1-5, 2010.

[22] H. Zhen, L. Yu, G. Ping, L. Y. Chen, "Evaluation on Equipment Maintenance Support Ability Based on FAHP," 4. https://doi.org/10.1109/QR2MSE, 6625854, 2013.

[23] S. Wang, X. Jia, Q. Hu, Q. Wei, "Effectiveness Evaluation of Equipment Maintenance Support System Based on Normal Grey Cloud Model," System Engineering and Electronic Technology, vol. 41, no. 07, pp. 1576-1582, 2019.

[24] S. Yang, D. Yang, W. Zhang, J. Huang, "Combat mission decomposition and mission modeling method," Firepower and Command Control, vol. 34, no. 08, pp. 24-29, 2009.

[25] T. Huang, J. Xiang, H. Yu, "Gray Assessment of Equipment Maintenance Support Capability Based on the Structure Entropy Weight Method," MATEC Web Conf., 02002. https://doi.org/10.1051/matecconf/201925602002, pp. 256, 2019.

[26] Z. Zhou, Y. Qian, Y. Liu, "System engineering method of product maintainability design," Systems ISSN: 0010-8189 
Engineering and Electronics, vol. 42, no. 05, pp. 1197-1204.

[27] S. Huang, M. Duan, X. Tang, Y. Chen, "Neural Network Evaluation Method and Application of Aviation Maintenance Support Ability," Aviation Maintenance and Engineering, no. 02, pp. 42-43, 2008.

[28] Y. Gu, Z. Cheng, "Effectiveness Evaluation of Wartime Equipment Maintenance Support Based on Bayesian Network," IOP Conf. Ser.: Mater. Sci. Eng., 052017, https://doi.org/10.1088/1757899X/569/5/052017, pp. 569, 2019. 